\title{
Lay People Training in CPR and in the Use of an Automated External Defibrillator, and Its Social Impact: A Community Health Study
}

\author{
Felipe Villalobos ${ }^{1}$, Albert Del Pozo ${ }^{2,3}$, Cristina Rey-Reñones $1,2,4, * \mathbb{C}$, Ester Granado-Font ${ }^{2,5}$, \\ David Sabaté-Lissner ${ }^{6}$, Carme Poblet-Calaf ${ }^{5}$, Josep Basora ${ }^{1,7}$, Antoni Castro ${ }^{7,8}$ and \\ Gemma Flores-Mateo ${ }^{2,9}$ \\ 1 Research Support Unit Tarragona-Reus, Fundació Institut Universitari per a la Recerca a l'Atenció Primària \\ de Salut Jordi Gol i Gurina (IDIAPJGol), Reus 43202, Spain \\ 2 Research Group in Primary Care Research Technologies (TICS-AP, Fundació Institut Universitari per a la \\ recerca a l'Atenció Primària de Salut Jordi Gol i Gurina (IDIAPJGol), Reus 43202, Spain \\ 3 Primary Care Centre Falset, Tarragona Regional Management, Catalan Institute of Health, \\ Tarragona 43730, Spain \\ 4 Nursing Department. University Rovira i Virgili. Tarragona 43002, Spain \\ 5 Primary Care Centre Horts de Miró, Tarragona Regional Management, Catalan Institute of Health, \\ Reus 43204, Spain \\ 6 Primary Care Centre CUAP, Tarragona Regional Management, Catalan Institute of Health, Reus 43202, Spain \\ 7 Faculty of Medicine and Health Sciences. Universitat Rovira i Virgili, Reus 43201, Spain \\ 8 Internal Medicine Department, Sant Joan de Reus University Hospital, Reus 43204, Spain \\ 9 Analysis and Quality Unit, Health and Social Network Santa Tecla, Tarragona 43003, Spain \\ * Correspondence: crey.tgn.ics@gencat.cat; Tel.: +34-977-778-515
}

Received: 23 July 2019; Accepted: 9 August 2019; Published: 11 August 2019

check for updates

\begin{abstract}
Out-of-hospital cardiac arrest (OHCA) mortality remains high. The best survival rates are achieved when trained people provide OHCA victims with cardiopulmonary resuscitation (CPR); however, it is estimated that only $25 \%$ of victims receive CPR. This community health study aims to evaluate the effectiveness of a training programme in basic CPR and in the use of an automatic external defibrillator (AED) on knowledge and skills for lay people, and its social impact. The training courses were based on Catalan Council of Resuscitation guidelines. Data were collected on sociodemographic characteristics, evaluation of knowledge and practical skills at baseline and at the end of the training courses, and also on the social impact of the programme. A total of 36 training courses with 482 participants were carried out, and most participants achieved a qualification of suitable. The mean score in knowledge was $3.1 \pm 1.1$ at baseline and $3.8 \pm 1.2(p=0.001)$ at the end of the programme. Participants rated the training courses as very satisfactory, considered the training useful, and felt more qualified to respond to an emergency. This study shows that a high percentage of participants acquired skills in basic CPR and use of an AED, which confirms the usefulness and effectiveness of training courses and its important social impact.
\end{abstract}

Keywords: out-of-hospital cardiac arrest; cardiopulmonary resuscitation; automatic external defibrillator; community health study

\section{Introduction}

Out-of-hospital cardiac arrest (OHCA) is a significant public health problem. In Europe, over 275,000 cases of OHCA are recorded every year [1]. In Spain, it is estimated that 24,500 cases of OHCA occur yearly, with mortality rates between $79.9 \%$ and $84.3 \%$ [2,3]. Mortality is mainly associated with 
the time gap between the cardiac arrest and the arrival of the Emergency Medical Services (EMS) [2-4]. It has been observed that OHCA survival is inversely proportional to the time elapsed between OHCA and cardiopulmonary resuscitation (CPR) initiation time. In our region (Catalonia, Spain), the response interval between alerting and arrival of EMS is usually greater than $8 \mathrm{~min}$ [5].

Since $70-85 \%$ OHCA cases occur at home and $15-25 \%$ in public spaces [6], programs that train the lay population in CPR remain crucial. Studies have demonstrated that community education and quality improvement programs to increase bystander and first-responder intervention, including CPR and defibrillation, and access to automatic external defibrillator (AED) are associated with improved outcomes, including survival [7-9]. However, most CPR training and guidelines to date have focused on healthcare personnel [10]. Unfortunately, in our population there are scarce data available about CPR training in bystanders (lay population) who are not healthcare personnel. Early CPR by a relative or lay population would achieve maximum effectiveness in the second link of the chain of survival, since CPR maneuvers would be initiated immediately after the loss of consciousness of the OHCA victim [4]. In Europe, $20-70 \%$ of OHCA victims receive basic CPR from a relative or a bystander, placing Spain in the penultimate place [11,12].

Several studies report that victims with better survival outcomes and quality of life after having suffered an OHCA are those who received CPR performed by a trained bystander [13-15]. Studies conducted in the United States between 2005 and 2010 observed that $27.4 \%$ of 31,689 cases of OHCA had better survival outcomes after receiving CPR [16]. In addition, CPR performed before the arrival of EMS more than doubled the 30-day survival rate [17].

Due to the high mortality of OHCA and the inadequate response of the lay population to a victim of OHCA, we proposed to conduct a community health intervention, which consisted of training lay people (i.e., individuals who are not healthcare personnel) in basic CPR and use of an AED, with the aim to provide skills in basic CPR and in use of an AED to create a network of qualified citizens able to carry out basic life support in the community.

\section{Material and Methods}

\subsection{Study Design}

Community health study conducted in the city of Reus (Catalonia, Spain; 100,000 inhabitants), which aimed to evaluate the effectiveness of a training programme in basic CPR and in the use of an AED on knowledge and skills for lay people, and its social impact. This study corresponds to Phase 2 of the SmartWatch Project. Study protocol details have been described elsewhere [18].

\subsection{Participants}

Participants were recruited by the research team and primary healthcare professionals, who explained the objectives of the study and offered training courses in basic CPR and use of an AED. People who decided to participate provided contact information (name and phone number). The research coordinator contacted the participants by phone to schedule the date, time, and place of the training course. Participation did not entail any remuneration or economic incentive.

Inclusion criteria were as follows: (1) relatives and/or caregivers of people with heart disease; (2) people who are in daily contact with patients at risk of OHCA (police, firefighters, teachers, shopkeepers, pharmacists, university students, gym instructors, and others); (3) and other adults interested in receiving the training.

According to data obtained from primary care electronic medical records and the database of the city's hospitals, in Reus 2105 people with heart disease are at risk of OHCA. The training courses aimed to train 430 people ( $20 \%$ of relatives of people with heart disease). 


\subsection{Training}

Knowledge and skills courses in basic CPR and use of an AED were carried out in accordance with Catalan Council of Resuscitation (CCR) guidelines [19], which follow European Resuscitation Guidelines [20]. The courses had a duration of $90 \mathrm{~min}$ and were delivered by instructors accredited by the CCR and a member of the research team as support staff. Each group comprised 8-10 participants per instructor and included one training mannequin (BRAYDEN ${ }^{\circledR}$ ) and one training AED (Saber One ${ }^{\circledR}$ ). The courses were free, and a certificate of attendance was provided after completion.

The BRAYDEN ${ }^{\circledR}$ training mannequin had an additional function that helped the instructor to visualize what happens with the blood flow to the brain based on the speed and depth of compressions. It consists of a lighting function that will only be lit when both compression depth (over $5 \mathrm{~cm}$ ) and speed are effective (over 100 per minute).

The AED Saber One ${ }^{\circledR}$ is a training defibrillator with three universal steps (turn on, place the electrodes, and defibrillate). In addition, this training unit has instructions and audio cues with a metronome for the appropriate number and rate of chest compressions (100 per minute) and two ventilations providing easy-to-follow CPR sequence for the participants.

\subsection{Variables}

Sociodemographic characteristics were collected at baseline: date of birth, gender, and social class (British Registrar General questionnaire [21]), which uses three categories: upper (I-II), middle $\left(\mathrm{III}_{\mathrm{N}}-\mathrm{III}_{\mathrm{M}}\right)$, and lower $(\mathrm{IV}-\mathrm{V})$.

At baseline and at the end of the training courses, an evaluation assessed the knowledge in basic CPR and AED use. An adaptation of four questions of the questionnaire proposed by the CCR was used: "Evaluation Test for Basic Life Support and Automatic Defibrillation (BLS-AED)" [22] (Figure 1). Each correct answer scored one point, and the results ranged from 0 to 4 .

Tick $(\mathrm{X})$ the answer you think is correct:

Question 1. Chest compressions for a cardiac arrest victim:

A) Must be performed at a frequency of 100 compressions per minute, maximum 120

B) Must be interrupted while the automatic external defibrillator (AED) is placed

C) Must be initiated as soon as possible and carried out with the minimum interruptions

D) Quality (frequency/depth) with which they are carried out has not importance

E) A and C are correct

Question 2. The compression/ventilation ratio for adult basic life support is:

A) $30: 2$

B) $15: 2$

C) $5: 1$

D) $50: 5$

E) No answer is correct

Question 3. The AED can be used in:

A) Adults

B) Children

C) Pregnant women

D) Adults over 75 years

E) All answers are correct

Question 4. If you have a cardiac arrest victim and the AED does an analysis of the rhythm and does not defibrillate, what should you do?

A) Start CPR immediately for 2 minutes

B) Place the patient in recovery position

C) Suspend cardiopulmonary resuscitation

D) Deactivate the AED

Figure 1. Questionnaire for assessing the knowledge in basic CPR and AED use. 
At the end of the training courses, the instructor evaluated the competence of each participant, in accordance with "Practical evaluation. BLS + AED sequence", proposed by the CCR [23]. Each item scored 1 point: (a) check scene; (b) assess level of consciousness; (c) open airway; (d) check spontaneous breathing; (e) ask for help; (f) chest compressions (quality); (g) frequency of compressions; (h) two ventilations (quality); (i) alternate compressions/ventilations. A trainee received the qualification of suitable when eight of the nine items evaluated were correctly performed. The training mannequin and AED were used to for the practice and for results measurement.

All participants were asked to respond to a course satisfaction questionnaire adapted by members of the research team, which contained three items: contents; methodology/organization; and course instructors. Score was on a scale of 1 (total dissatisfaction) to 5 (total satisfaction).

\subsection{Social Impact}

Six months after the end of the training courses, the social impact of training in basic CPR and AED use was evaluated. The members of the research team sent a text message to all participants with a link to an online survey validated for the Spanish population [24].

\subsection{Statistical Analysis}

The quantitative variables were expressed as mean and standard deviation, and the categorical variables as percentages. The $\chi^{2}$ test was used to compare categorical variables in different groups. Unpaired Student's $t$-test was used to compare continuous variables and the paired Student's $t$-test was used to compare values between different time-points (baseline and end of the training courses) for continuous variables, while the McNemar test was used for the categorical variables.

Statistical significance was set at a $p$ value $<0.05$. SPSS for Windows Version 22.0 (IBM Corp. Released 2013. IBM SPSS Statistics for Windows, Version 22.0. Armonk, NY, USA) was used for the analysis.

\section{Results}

\subsection{Sociodemographic Characteristics}

From September 2017 to October 2018, 36 training courses where 482 participants were trained in CPR and AED use were conducted (Figure 2). A total of 50.8\% trained participants were women; mean age was $45.7( \pm 2.5)$ years; $73.5 \%$ participants were in active employment and $48.7 \%$ were middle class; the group with the highest representation was the general population $(60.8 \%)$ (Table 1$)$.

Table 1. Sociodemographic characteristics of participants.

\begin{tabular}{lc}
\hline & Participants $(\boldsymbol{n}=\mathbf{4 8 2}) \mathbf{\%}$ \\
\hline Age (years) ${ }^{*}$ & $45.7(2.8)$ \\
\hline Women & 50.8 \\
\hline Employment status & \\
Currently working & 73.5 \\
Unemployed & 5.8 \\
Retired & 9.5 \\
Housewife & 3.4 \\
Student & 5.8 \\
Disability & 1.3 \\
\hline Social class & \\
Lower class (IV-VI) & 14.1 \\
Middle class (III $\left.{ }_{\mathrm{N}}-\mathrm{III}_{\mathrm{M}}\right)$ & 48.7 \\
Upper class (I-II) & 37.2 \\
\hline
\end{tabular}


Table 1. Cont.

\begin{tabular}{lc}
\hline & Participants $(n=482) \%$ \\
\hline Group & \\
General population & 60.8 \\
Catalan Police & 13.9 \\
Firefighters & 9.8 \\
National Police & 5.4 \\
Gym instructors & 6.4 \\
Teaching staff & 3.1 \\
University students & 0.6 \\
\hline \multicolumn{2}{c}{${ }^{*}$ Values expressed as mean and (SD). }
\end{tabular}

* Values expressed as mean and (SD).

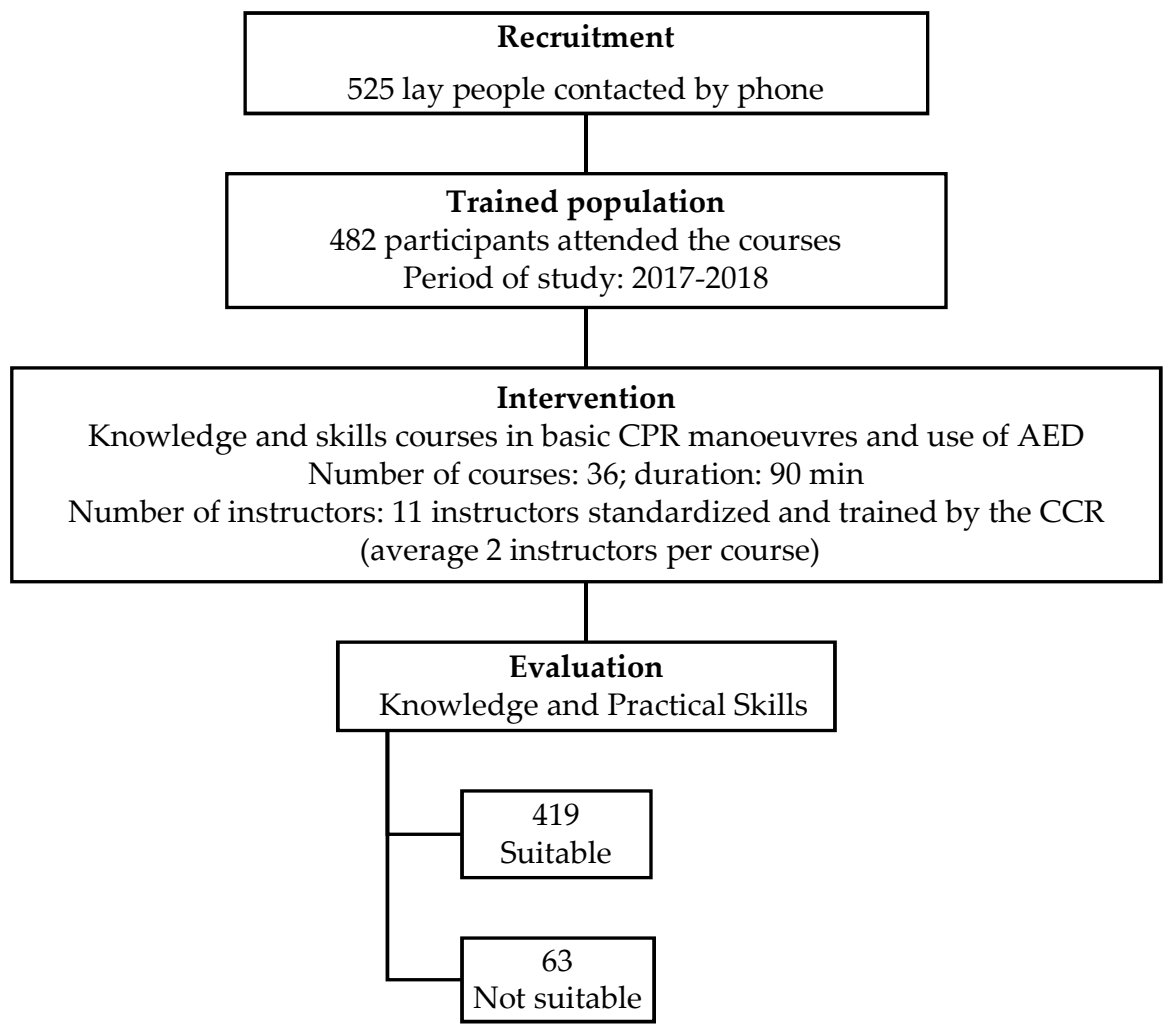

Figure 2. Study flowchart.

\subsection{Training Evaluation}

After evaluating knowledge and practical skills, 419 participants were considered suitable to perform CPR and AED use. The instructors took into account the additional function of the training mannequin (explained above) for practical skills measure of the participants.

In relation to the evaluation of knowledge in basic CPR and AED use, at the end of the courses knowledge had improved (from $3.17 \pm 1.2$ to $3.80 \pm 1.1$ points, $p=0.001$ ) and the percentage of participants who responded correctly to each question of the questionnaire increased (Figure 3). In the analysis of knowledge, the firefighters were the group with more correct answers at the beginning and end of the training $(p<0.05)$ (Table 2). 


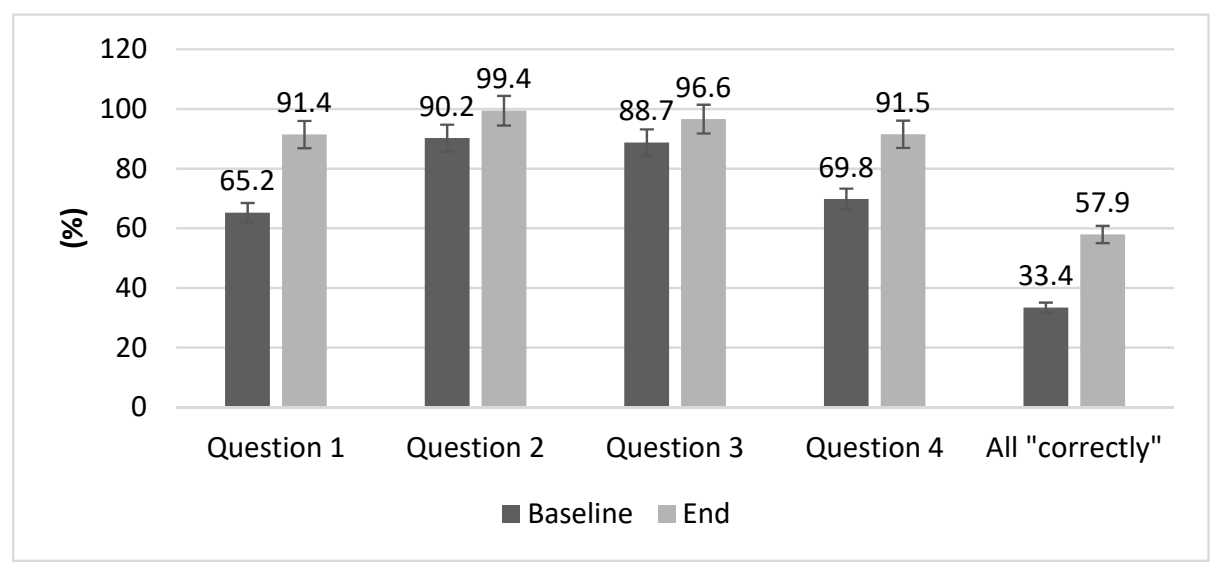

Figure 3. Percentages of participants who responded correctly to the evaluation questionnaire at baseline and the end of the training. Values expressed in percentage. All questions: $p<0.05$ between different time-points (baseline and at the end of the training courses).

Table 2. Percentage of participants who responded correctly to the evaluation questionnaire at baseline and at the end of the training courses by groups.

\begin{tabular}{lcccccccc}
\hline \multirow{2}{*}{ Group } & \multicolumn{2}{c}{ Question 1 } & \multicolumn{2}{c}{ Question 2 } & \multicolumn{2}{c}{ Question 3 } & \multicolumn{2}{c}{ Question 4 } \\
\cline { 2 - 9 } & Baseline & End & Baseline & End & Baseline & End & Baseline & End \\
\hline General population * & 60.6 & 93.5 & 88 & 99 & 88.9 & 97.5 & 67.7 & 92.1 \\
Catalan police * & 51.1 & 85.7 & 95.3 & 100 & 90.5 & 100 & 69.4 & 78.8 \\
Firefighters * & 93.3 & 100 & 100 & 100 & 91.5 & 97.6 & 88.9 & 100 \\
National police * & 56.5 & 56.2 & 78.3 & 100 & 73.9 & 60 & 65 & 93.3 \\
Gym instructors * & 74.1 & 91.7 & 93.5 & 100 & 90 & 100 & 63.3 & 92.3 \\
Teaching staff * & 78.6 & 93.3 & 75 & 100 & 93.3 & 100 & 68.3 & 100 \\
University students * & 66.7 & 100 & 100 & 100 & 66.7 & 100 & 66.7 & 100 \\
\hline
\end{tabular}

Values expressed in percentages. ${ }^{*} p<0.05$ for each question between different time-points (baseline and at the end of the training courses).

Table 3 shows the results of the training course satisfaction questionnaire. Most participants were satisfied with the training courses, they expressed intention to apply the knowledge learned, and considered necessary to transmit what they had learned to others.

Table 3. Training course satisfaction questionnaire.

\begin{tabular}{lc}
\hline & Participants $(n=361)$ \\
\hline $\begin{array}{l}\text { Contents } \\
\text { The topics were addressed correctly }\end{array}$ & $4.60(0.49)$ \\
\hline $\begin{array}{l}\text { Methodology/Organization } \\
\text { The duration of the training course was appropriate }\end{array}$ & $4.64(0.49)$ \\
\hline Course instructors & $4.63(0.51)$ \\
$\begin{array}{l}\text { The environmental conditions (classroom, furniture, resources } \\
\text { used) were adequate to facilitate the training process }\end{array}$ & $4.73(0.45)$ \\
The instructor handled the topics well & \\
\hline $\begin{array}{l}\text { Appreciation } \\
\text { The instructor motivated the participants }\end{array}$ & $4.75(0.43)$ \\
The training course has been useful & $4.77(0.42)$ \\
\hline
\end{tabular}

Values expressed in mean and (SD). Rank 1-5. 


\subsection{Social Impact}

Table 4 reports the evaluation of the social impact of training in basic CPR and AED use. Of 411 participants contacted by text message, only 207 answered the survey (50.36\%). Up to $89.9 \%$ of surveyed participants reported knowing the meaning of OHCA, $86.6 \%$ would be able to identify a victim of OHCA, and a high percentage of participants would recognize a public access AED device. In addition, $28.5 \%$ participants reported having witnessed an OHCA on at least one occasion, and of these more than half $(52.5 \%)$ had tried to perform basic CPR. All participants considered important for the lay population to be trained in basic CPR, in order to assist any victim of OHCA.

Table 4. Social impact of training in basic cardiopulmonary resuscitation (CPR) and automated external defibrillator (AED) use.

\begin{tabular}{lc}
\hline & Participants $(\boldsymbol{n}=\mathbf{2 0 7}) \mathbf{\%}$ \\
\hline Do you know the meaning of OHCA? & 89.9 \\
Would you know how to identify a victim of OHCA? & 86.6 \\
Would you be able to recognize a public access AED device? & 82.1 \\
Have you ever witnessed an OHCA? & 28.5 \\
Have you ever tried to perform basic CPR? & 15.9 \\
Considers important knowledge in basic CPR & 100 \\
\hline
\end{tabular}

OHCA $=$ out-of-hospital cardiac arrest. $\mathrm{AED}=$ automated external defibrillator, $\mathrm{CPR}=$ cardiopulmonary resuscitation.

When asked for their opinion regarding training in basic CPR and AED use at the end of the survey, most respondents agreed on the following: (a) training courses should be introduced to pupils in primary and secondary schools; (b) the general population should be informed on the location and availability of AED devices in the city; and (c) courses should be carried out more frequently to keep the training up to date.

\section{Discussion}

This community health study evaluated knowledge and skills training in basic CPR and AED use in the lay population. The results showed that a significant percentage of participants acquired sufficient skills in basic CPR and AED use, confirming the usefulness and effectiveness of these courses.

One of the strengths of the study is that the programme was based on Catalan Council of Resuscitation recommendations [19], which follow European Resuscitation Guidelines [20], and allow standardization of knowledge in the lay population. In addition, each instructor was in charge of only 8-10 participants, and mannequins with simulated cases were used for practicing. Several studies indicate that in order to acquire the appropriate skills, CPR maneuvers should be repeatedly applied on mannequins in small groups until the execution becomes automatic [25-28].

This intervention programme trained 482 participants, more than the initial 430 anticipated, which corresponded to $20 \%$ relatives of patients with heart disease registered in the city. CPR international guidelines underscore that any person who is unresponsive and does not breathe normally should be recognized as a victim of OHCA, and once the victim is identified, the EMS should be immediately activated, and witnesses should begin CPR maneuvers until the arrival of the AED and healthcare professionals. Within these guidelines, community health programs of CPR training that educate the lay population remain essential, with special attention to the populations at risk [20,29].

Our results show that $86.9 \%$ of the trained participants acquired adequate CPR skills. Similar results were observed in a study conducted in the Spanish general population, where $87.2 \%$ participants were adequately prepared [26]. In contrast, a study conducted in Spanish high-school students reported lower percentages (58\%) [30]. In other countries, similar percentages of participants of various lay population groups achieved sufficient training in CPR and AED use [25,27,31,32].

In our courses, older people with musculoskeletal problems were unable to practice on mannequins and did not attain sufficient CPR skills. A recent study agreed that physical limitation, lack of confidence, 
and having to practice in large groups were barriers to CPR training in the older population (over 55 years) [33]. Although this group is considered more at risk of OHCA than potential witness, it is essential that they also acquire CPR skills.

At the end of the programme, CPR knowledge increased, meaning that most participants understood the frequency of compressions, compression/ventilation ratios and use of the AED. These results are consistent with other studies conducted in the Spanish population. For instance, high-school students [26] and students from the nursing and physiotherapy degrees [34] showed an increase of knowledge regarding CPR at the end of the training, and university students improved skills in AED use [35]. These studies had longer duration times than ours ( $20 \mathrm{~h}$ in 8 sessions, $4 \mathrm{~h}$ and $120 \mathrm{~min}$, respectively). In this respect, our results show that even with limited time and resources, $90 \mathrm{~min}$ of CPR training would significantly increase dissemination in the community.

Statistically significant differences were found when comparing the results on knowledge between groups, with firefighters scoring highest at the end of the training. Firefighters, together with the EMS and the police, are usually amongst the first responders to OHCA victims, and consequently CPR and use of the AED is part of their professional training. The inclusion of firefighters in an active network of trained volunteers would increase the survival rate of OHCA in urban and rural areas [36-38].

Community health studies indicate the social impact of interventions in the community. In this case, training in basic CPR and AED use in the lay population is expected to have a significant social impact, since a high percentage of trained participants learned to identify cardiac arrest and public access AED devices. In contrast, a recent survey conducted in northern Spain that explored knowledge and attitude with regard to OHCA and CPR techniques, reported that $73 \%$ of respondents knew what cardiac arrest was, but only $45 \%$ declared that if they witnessed one they would be able to identify it, and only $60 \%$ knew how to identify a public access AED device [24]. Similar results were observed in surveys conducted in other European countries [17,39].

Future strategies for CPR training and AED use should take into account the suggestions made by a high percentage of participants, namely to introduce training in primary and secondary schools, to update skills regularly, and to disseminate the knowledge of public access AED devices in the community. Several studies report that CPR training in schools is key to the dissemination of CPR in communities, adding students as potential resuscitators of OHCA victims [40,41].

Few studies evaluate the effect of the dissemination of public access AED devices. A recent study conducted in Japan observed that the increase in the use of public access AED devices by bystanders was associated with an increase in the number of OHCA survivors, with fewer neurological complications [42]. It is therefore essential to implement public health strategies to disseminate easily accessible AED devices in the community.

\section{Conclusions}

This training programme improved knowledge and skills in basic CPR and in the use of an AED and had a high social impact at community level. We think that it is very important to evaluate the level of knowledge and skills in CPR and use of an AED. Training in basic CPR and use of an AED is a key element of the chain of survival for OHCA, early activation of emergency medical services, immediate bystander provision of $\mathrm{CPR}$, and rapid defibrillation could improve survival outcomes and quality of life for OHCA victims.

Author Contributions: F.V. coordinated the study, participated in the study design and in the drafting of the manuscript. A.D.P. coordinated the study, was responsible for the study design and participated in the drafting of the manuscript. C.R.-R. is the principal investigator, coordinated the study, participated in the study design and in the drafting of the manuscript. E.G.-F., D.S.-L., C.P.-C., J.B., A.C. and G.F.-M. are members of the research team and participated in the drafting of the manuscript. All authors have read and approved the manuscript.

Funding: This project has been funded by the Royal Academy of Medical Sciences Prize, the Catalan Council of Resuscitation Prize and the 2016 call for proposals within the Strategic Plan of Research and Innovation in Health (PERIS) 2016-2020 for Primary Care Research Projects (Code SLT002/16/0162) of the Health Department of the Generalitat de Catalunya. 
Acknowledgments: We thank the following CPR instructors: Coral Chancho, Cristina Piñol, Emma Cañejas, Joaquina Sánchez, María Luisa Fores, María Isabel Sánchez-Oro, Pilar Llobet, Ramón Sagarra and Rosa García. We are also thankful for the assistance provided by the Primary Health Care Research Institute IDIAP Jordi Gol and the clinical and administrative staff of the participating Primary Health Care Centres.

Conflicts of Interest: The authors declare no conflict of interest.

\section{References}

1. Berdowski, J.; Berg, R.A.; Tijssen, J.G.P.; Koster, R.W. Global incidences of out-of-hospital cardiac arrest and survival rates: Systematic review of 67 prospective studies. Resuscitation 2010, 81, 1479-1487. [CrossRef] [PubMed]

2. Requena-Morales, R.; Palazón-Bru, A.; Rizo-Baeza, M.M.; Adsuar-Quesada, J.M.; Gil-Guillén, V.F.; Cortés-Castell, E. Mortality after out-of-hospital cardiac arrest in a Spanish Region. PLoS ONE 2017, 12, e0175818. [CrossRef] [PubMed]

3. Ballesteros-Peña, S.; Abecia-Inchaurregui, L.C.; Echevarría-Orella, E. Factors Associated with Mortality in Out-of-hospital Cardiac Arrests Attended in Basic Life Support Units in the Basque Country (Spain). Rev. Española Cardiol. (Engl. Ed.) 2012, 66, 269-274.

4. Ballesteros-Peña, S. Supervivencia extrahospitalaria tras una parada cardiorespiratoria en España: Una revisión de la literatura. Emerg. Rev. La Soc. Española Med. Urgenc. Emerg. 2013, 25, 137-142.

5. Sociedad Española de Medicina Intensiva, Crítica y Unidades Coronarias (SEMICYUC). La cadena de supervivencia. In Plan Nacional RCP-Semicyuc; SEMICYUC: Madrid, Spain, 2012; pp. 1-2.

6. García Guasch, R.; Cerdà, M. Enseñanza de la reanimación cardiopulmonar a la población: Uno de los pilares para mejorar la supervivencia de los pacientes en paro cardíaco. Med. Clin. (BARC) 2005, 124, 13-15. [CrossRef]

7. Fordyce, C.B.; Hansen, C.M.; Kragholm, K.; Dupre, M.E.; Jollis, J.G.; Roettig, M.L.; Becker, L.B.; Hansen, S.M.; Hinohara, T.T.; Corbett, C.C.; et al. Association of Public Health Initiatives with Outcomes for Out-of-Hospital Cardiac Arrest at Home and in Public Locations. JAMA Cardiol. 2017, 2, 1226. [CrossRef]

8. Stokes, N.A.; Scapigliati, A.; Trammell, A.R.; Parish, D.C. The Effect of the AED and AED Programs on Survival of Individuals, Groups and Populations. Prehosp. Disaster Med. 2012, 27, 419-424. [CrossRef]

9. Hansen, C.M.; Kragholm, K.; Pearson, D.A.; Tyson, C.; Monk, L.; Myers, B.; Nelson, D.; Dupre, M.E.; Fosbøl, E.L.; Jollis, J.G.; et al. Association of bystander and first-responder intervention with survival after out-of-hospital cardiac arrest in North Carolina, 2010-2013. JAMA J. Am. Med. Assoc. 2015, 314, 255-264. [CrossRef]

10. Smith, G.B.; Welch, J.; DeVita, M.A.; Hillman, K.M.; Jones, D. Education for cardiac arrest-Treatment or prevention? Resuscitation 2015, 92, 59-62. [CrossRef]

11. Gräsner, J.-T.; Bossaert, L. Epidemiology and management of cardiac arrest: What registries are revealing. Best Pract. Res. Clin. Anaesthesiol. 2013, 27, 293-306. [CrossRef]

12. Clark, A.P.; Aldridge, M.D.; Guzzetta, C.E.; Nyquist-Heise, P.; Norris, R.M.; Loper, P.; Meyers, T.A.; Voelmeck, W. Family Presence During Cardiopulmonary Resuscitation. Crit. Care Nurs. Clin. North Am. 2005, 17, 23-32. [CrossRef] [PubMed]

13. Stiell, I.G.; Nichol, G.; Wells, G.; De Maio, V.; Nesbitt, L.; Blackburn, J.; Spaite, D. Health-Related Quality of Life Is Better for Cardiac Arrest Survivors Who Received Citizen Cardiopulmonary Resuscitation. Circulation 2003, 108, 1939-1944. [CrossRef] [PubMed]

14. Haydon, G.; van der Riet, P.; Maguire, J. Survivors' quality of life after cardiopulmonary resuscitation: An integrative review of the literature. Scand. J. Caring Sci. 2017, 31, 6-26. [CrossRef] [PubMed]

15. Hollenberg, J.; Herlitz, J.; Lindqvist, J.; Riva, G.; Bohm, K.; Rosenqvist, M.; Svensson, L. Improved Survival After Out-of-Hospital Cardiac Arrest Is Associated with an Increase in Proportion of Emergency Crew-Witnessed Cases and Bystander Cardiopulmonary Resuscitation. Circulation 2008, 118, 389-396. [CrossRef] [PubMed]

16. Centers for Disease Control and Prevention. Out-of-Hospital Cardiac Arrest Surveillance-Cardiac Arrest Registry to Enhance Survival (CARES), United States, October 1, 2005-December 31, 2010. Surveill. Summ. 2011, 60, 1-19. 
17. Hasselqvist-Ax, I.; Riva, G.; Herlitz, J.; Rosenqvist, M.; Hollenberg, J.; Nordberg, P.; Ringh, M.; Jonsson, M.; Axelsson, C.; Lindqvist, J.; et al. Early Cardiopulmonary Resuscitation in Out-of-Hospital Cardiac Arrest. N. Engl. J. Med. 2015, 372, 2307-2315. [CrossRef] [PubMed]

18. Del Pozo, A.; Villalobos, F.; Rey-Reñones, C.; Granado, E.; Sabaté, D.; Poblet, C.; Calvet, A.; Basora, J.; Castro, A.; Flores, G. Effectiveness of a network of automatically activated trained volunteers on the reduction of cardiopulmonary resuscitation manoueuvers initiation time: Study protocol. BMC Public Health 2019, 19, 572. [CrossRef]

19. Consell Català de Resusscitació. Ressuscitació Cardiopulmonar. In Manual de l'alumne; CCR: Barcelona, Spain, 2010.

20. Monsieurs, K.G.; Nolan, J.P.; Bossaert, L.L.; Greif, R.; Maconochie, I.K.; Nikolaou, N.I.; Perkins, G.D.; Soar, J.; Truhlář, A.; Wyllie, J.; et al. European Resuscitation Council Guidelines for Resuscitation 2015. Resuscitation 2015, 95, 1-80. [CrossRef]

21. Domingo, A.; Marcos, J. Propuesta de un indicador de la «clase social» basado en la ocupación. Gac. Sanit. 1989, 3, 320-326. [CrossRef]

22. Consell Català de Resusscitació. Test avaluació Suport Vital Bàsic i Desfibrilació Automàtica (SVB-DEA); CCR: Barcelona, Spain, 2010.

23. Consell Català de Resusscitació. Avaluació pràctica. Seqüència SVB + DEA; CCR: Barcelona, Spain, 2010.

24. Ballesteros-Peña, S.; Fernández-Aedo, I.; Pérez-Urdiales, I.; García-Azpiazu, Z.; Unanue-Arza, S. Conocimientos y actitudes de los ciudadanos del País Vasco sobre la resucitación cardiopulmonar y los desfibriladores externos automatizados. Med. Intensiva 2016, 40, 75-83. [CrossRef]

25. Riggs, M.; Franklin, R.; Saylany, L. Associations between cardiopulmonary resuscitation (CPR) knowledge, self-efficacy, training history and willingness to perform CPR and CPR psychomotor skills: A systematic review. Resuscitation 2019, 138, 259-272. [CrossRef] [PubMed]

26. Carrera, M.J.S.; García, L.M.G.; Nieto, F.B.; Cid, J.L.; Álvarez, A.C. Enseñanza de la reanimación cardiopulmonar básica en población general. Atención Primaria 2004, 34, 408-413. [CrossRef]

27. Cartledge, S.; Bray, J.E.; Leary, M.; Stub, D.; Finn, J. A systematic review of basic life support training targeted to family members of high-risk cardiac patients. Resuscitation 2016, 105, 70-78. [CrossRef]

28. García-Suárez, M.; Méndez-Martínez, C.; Martínez-Isasi, S.; Gómez-Salgado, J.; Fernández-García, D. Basic life support training methods for health science students: A systematic review. Int. J. Environ. Res. Public Health 2019, 16, 768. [CrossRef] [PubMed]

29. Messa, J.B.L. Is the Spanish population aware and capable of acting in response to cardiac arrest? Med. Intensiva 2016, 40, 73-74.

30. Miró, Ò.; Jiménez-Fábrega, X.; Díaz, N.; Coll-Vinent, B.; Bragulat, E.; Jiménez, S.; Espinosa, G.; Hernández-Rodríguez, J.; García-Alfranca, F.; Álvarez, M.T.; et al. Programa de Reanimación cardiopulmonar Orientado a Centros de Enseñanza Secundaria (PROCES): Análisis de los resultados del estudio piloto. Med. Clin. (BARC) 2005, 124, 4-9. [CrossRef] [PubMed]

31. Moon, S.; Ryoo, H.W.; Ahn, J.Y.; Park, J.B.; Lee, D.E.; Kim, J.H.; Jin, S.; Lee, K.W. A 5-year change of knowledge and willingness by sampled respondents to perform bystander cardiopulmonary resuscitation in a metropolitan city. PLOS ONE 2019, 14, e0211804. [CrossRef]

32. Nishiyama, C.; Kitamura, T.; Sakai, T.; Murakami, Y.; Shimamoto, T.; Kawamura, T.; Yonezawa, T.; Nakai, S.; Marukawa, S.; Sakamoto, T.; et al. Community-wide dissemination of bystander cardiopulmonary resuscitation and automated external defibrillator use using a 45-min chest compression-only cardiopulmonary resuscitation training. J. Am. Heart Assoc. 2019, 8, 1-10. [CrossRef]

33. Vaillancourt, C.; Charette, M.; Kasaboski, A.; Brehaut, J.C.; Osmond, M.; Wells, G.A.; Stiell, I.G.; Grimshaw, J. Barriers and facilitators to CPR knowledge transfer in an older population most likely to witness cardiac arrest: A theory-informed interview approach. Emerg. Med. J. 2014, 31, 700-705. [CrossRef]

34. Méndez-Martínez, C.; Martínez-Isasi, S.; García-Suárez, M.; Peña-Rodríguez, M.A.D.L.; Gómez-Salgado, J.; Fernández-García, D. Acquisition of Knowledge and Practical Skills after a Brief Course of BLS-AED in First-Year Students in Nursing and Physiotherapy at a Spanish University. Int. J. Environ. Res. Public Health 2019, 16, 766. [CrossRef] 
35. Basanta Camiño, S.; Navarro Patón, R.; Freire Tellado, M.; Barcala Furelos, R.; Pavón Prieto, M.P.; Fernández López, M.; Neira Pájaro, M.A. Evaluación del conocimiento y de las habilidades para el uso de un Desfibrilador Externo Automatizado (DEA) por estudiantes universitarios. Un diseño cuasiexperimental. Med. Intensiva 2017, 41, 270-276. [CrossRef] [PubMed]

36. Nordberg, P.; Jonsson, M.; Forsberg, S.; Ringh, M.; Fredman, D.; Riva, G.; Hasselqvist-Ax, I.; Hollenberg, J. The survival benefit of dual dispatch of EMS and fire-fighters in out-of-hospital cardiac arrest may differ depending on population density-A prospective cohort study. Resuscitation 2015, 90, 143-149. [CrossRef] [PubMed]

37. Myerburg, R.J.; Fenster, J.; Velez, M.; Rosenberg, D.; Lai, S.; Kurlansky, P.; Newton, S.; Knox, M.; Castellanos, A. Impact of community-wide police car deployment of automated external defibrillators on survival from out-of-hospital cardiac arrest. Circulation 2002, 106, 1058-1064. [CrossRef] [PubMed]

38. Saner, H.; Morger, C.; Eser, P.; von Planta, M. Dual dispatch early defibrillation in out-of-hospital cardiac arrest in a mixed urban-rural population. Resuscitation 2013, 84, 1197-1202. [CrossRef] [PubMed]

39. Strömsöe, A.; Andersson, B.; Ekström, L.; Herlitz, J.; Axelsson, Å.; Göransson, K.E.; Svensson, L.; Holmberg, S. Education in cardiopulmonary resuscitation in Sweden and its clinical consequences. Resuscitation 2010, 81, 211-216. [CrossRef] [PubMed]

40. Böttiger, B.W.; Bossaert, L.L.; Castrén, M.; Cimpoesu, D.; Georgiou, M.; Greif, R.; Grünfeld, M.; Lockey, A.; Lott, C.; Maconochie, I.; et al. Kids Save Lives-ERC position statement on school children education in CPR.: "Hands that help—Training children is training for life". Resuscitation 2016, 105, A1-A3.

41. Cave, D.M.; Aufderheide, T.P.; Beeson, J.; Ellison, A.; Gregory, A.; Hazinski, M.F.; Hiratzka, L.F.; Lurie, K.G.; Morrison, L.J.; Mosesso, V.N.; et al. Importance and Implementation of Training in Cardiopulmonary Resuscitation and Automated External Defibrillation in Schools. Circulation 2011, 123, 691-706. [CrossRef] [PubMed]

42. Kitamura, T.; Kiyohara, K.; Sakai, T.; Matsuyama, T.; Hatakeyama, T.; Shimamoto, T.; Izawa, J.; Fujii, T.; Nishiyama, C.; Kawamura, T.; et al. Public-Access Defibrillation and Out-of-Hospital Cardiac Arrest in Japan. N. Engl. J. Med. 2016, 375, 1649-1659. [CrossRef]

(C) 2019 by the authors. Licensee MDPI, Basel, Switzerland. This article is an open access article distributed under the terms and conditions of the Creative Commons Attribution (CC BY) license (http://creativecommons.org/licenses/by/4.0/). 